\title{
Preparation and Characterization of Oligomer from Recycled PET and Evaluated as a Corrosion Inhibitor for C-Steel Material in $0.1 \mathrm{M} \mathrm{HCl}$
}

\author{
Ali H. Yasir, Alaa S. Khalaf, Moayad N. Khalaf* \\ Chemistry Department, College of Science, Basrah University, Basrah, Iraq \\ Email: *moayad_khalaf@yahoo.com
}

How to cite this paper: Yasir, A.H., Khalaf, A.S. and Khalaf, M.N. (2017) Preparation and Characterization of Oligomer from Recycled PET and Evaluated as a Corrosion Inhibitor for C-Steel Material in $0.1 \mathrm{M} \mathrm{HCl}$. Open Journal of Organic Polymer Materials, 7, 1-15.

http://dx.doi.org/10.4236/ojopm.2017.71001

Received: November 29, 2016

Accepted: January 10, 2017

Published: January 13, 2017

Copyright $\odot 2017$ by authors and Scientific Research Publishing Inc. This work is licensed under the Creative Commons Attribution International License (CC BY 4.0).

http://creativecommons.org/licenses/by/4.0/

\begin{abstract}
Polyethylene terephthalate waste (PET) was depolymerized by thiodiglycol into thioglycolyzed product. The product was characterized by FTIR and ${ }^{1}$ HNMR spectroscopy and the thermal properties (TGA, DTA) showed that the prepared compound was thermally stable until $250^{\circ} \mathrm{C}$. The efficiency of the prepared corrosion inhibitor for carbon steel was measured by using acid media $(0.1 \mathrm{HCl})$ as corrosive environment and the inhibitor concentration was $(0,10,20,30,40$ and $50 \mathrm{ppm})$. The electrochemical technique used Tafel plot to measure the efficiency of inhibitor. Factors effect on the rate of corrosion like temperature $(298,308,318,328 \mathrm{~K})$ and concentration $(10,20,30,40$, $50 \mathrm{ppm}$ ) of inhibitor were studied. From the obtained results many factors were calculated that determined the efficiency of the inhibitor like corrosion rate, charge transfer resistance and inhibitor efficiency. It was observed that the corrosion rate and charge transfer of the carbon steel for the inhibitor increase with increase of temperature and decrease with increase of the inhibitor concentration in the same temperature. The results showed that the inhibitor had high inhibition in reducing the corrosion rate. The inhibition efficiency (\% IE) reached $97.1 \%$ for the $40 \mathrm{ppm}$ concentration at $308 \mathrm{~K}$.
\end{abstract}

\section{Keywords}

Waste Polymer, Glycolysis, Corrosion Inhibitor

\section{Introduction}

PET introduced to consumers as the plastic soft drink bottle in the 1970s, then PET quickly gained acceptance among bottlers and consumers [1] [2] [3]. Because 
PET have lightweight, economical and shatter proof, PET plastic offered unique marketing and lifestyle benefits. The chemical nature of polyethylene terephthalate permits easy recyclability by all known recycling methods. Recycling of PET has become an important process from the environmental point of view and it has given commercial opportunity due to wide spread use and availability of PET bottles, packages and fibers [4] [5] [6] [7]. Corrosion is the destructive attack of a material by reaction with its environment [8]. Corrosion is a chemical or electrochemical oxidation process, in which the metal transfer electrons to the environment and undergoes a valance change from zero to a positive value. The serious consequences of the corrosion process have become a problem of worldwide significance [9] [10] [11]. Corrosion control is achieved by recognizing and understanding corrosion mechanisms, using corrosion-resistant materials and altering designs, also by using protective systems, devices, and treatments [12]. Organic inhibitor is applied extensively to protect metals from corrosion in many aggressive acidic media. In the present study waste PET-bottles were depolarized using ethylene glycol to produce (Bis(2-((2-hydroxyethyl)thio) ethyl) terephthalate, the produce compound was tested as corrosion inhibitor.

\section{Materials and Methods}

\subsection{Materials}

C-steel (C1010) was obtained from Metal Samples (USA) was used with the following composition by percentage weight: $\mathrm{C}=0.13, \mathrm{Mn}=0.3, \mathrm{Si}=0.37, \mathrm{P}=$ $0.04, \mathrm{~S}=0.05, \mathrm{Cr}=0.1, \mathrm{Ni}=0.3, \mathrm{Cu}=0.3, \mathrm{AS}=0.08$ and the remainder is Fe. Poly(ethyleneterphthalate) (PET) waste is collected from beverage bottles. Thiodiglycol, Zinc acetate and $\mathrm{HCl}$ were obtained from Aldrich Chemical Co.

\subsection{Experimental Methods}

\subsubsection{Electrochemical Measurements}

The electrochemical measurements were performed using a potentiostat/galvanostat (ACM) connected to a computer. A three electrode cell assembly, consisting of a C-steel rod embedded in araldite as the working electrode (WE), a platinum sheet as the counter electrode (CE) and a saturated calomel electrode as the reference electrode (RE), was used for the electrochemical measurements. The temperature of the electrolyte was maintained at the required temperature using a water bath. Before immersion in the test solutions, the WE was polished with a polishing machine using emery paper from 600 to 1200 grade until a mirror image was obtained. Then, the WE was washed with distilled water then immersed in acetone for 1 minute in an ultrasonic cleaner. The WE electrode was prepared directly before electrochemical measurements then immersed in the test solution at open circuit potential for one hour until a steady state potential was obtained before impedance and polarization measurements were performed. All experiments were performed in aerated solutions. From the polarization data, were calculated like the degree of surface coverage $(\theta)$, the percen- 
tage inhibition efficiency (\% IE), corrosion rate and charge transfer resistance [13].

\subsubsection{Recycling Process}

The reaction of PET waste was depolymerized with Thiodiglycol, at weight ratio of PET to Thiodiglycol 1:8 (wt $\%$ of PET: wt\% of Thiodiglycol) using $0.5 \%$ of Zinc acetate as catalyst (by weight based on weight of PET). The reaction mixtures were heated under vigorous stirring in nitrogen atmosphere at temperature about $160^{\circ} \mathrm{C}-180^{\circ} \mathrm{C}$ for $10 \mathrm{~h}$ and at $140^{\circ} \mathrm{C}$ for $2 \mathrm{~h}$. The temperature of the reaction was then lowered to $100^{\circ} \mathrm{C}$ for $1 \mathrm{~h}$. The mixture was allowed to cool to room temperature. at the end of the reaction, distilled water was added in excess to the reaction mixture with vigorous agitation to precipitate oligomer of Bis(2-((2-hydroxyethyl)thio)ethyl terephthalate (BHET) out of the product, black liquid viscous of (BHET) was obtained [14] [15], the suggested mechanism was shown in (Figure 1), The chemical structure of (BHET) was confirmed from their FTIR (Figure 2) and 1HNMR (Figure 3) spectroscopy.

\subsubsection{Characterization for Inhibitor}

Figure 2 shows the FTIR spectra of (BHET). From the FTIR spectra a strong peak at wavelength $\left(3396 \mathrm{~cm}^{-1}\right)$ attributable to group $(\mathrm{O}-\mathrm{H})$, while the peak at $\left(1718 \mathrm{~cm}^{-1}\right)$ is attributed to the ester carbonyl groups [16] and the strong peak at $\left(1105 \mathrm{~cm}^{-1}\right)$ attributable to bond (C-O) ester association. The peak at $810 \mathrm{~cm}^{-1}$ for (BHET) is assigned to $-\mathrm{CH}$ out of plane bending of substituted phenyl.

Figure 3 shows the ${ }^{1} \mathrm{HNMR}$ of (BHET), the peak at ( $\left.8.11 \mathrm{ppm}\right)$ is singlet for proton aromatic ring (a). The $\mathrm{OH}$ group (b) show a singlet peak at $(4.87 \mathrm{ppm})$, and peak triple (c) which is attributed to the group of methylene nearest carbonyl ester at $(4.53 \mathrm{ppm})$, and peak (d) powerful Triplet attributable to the

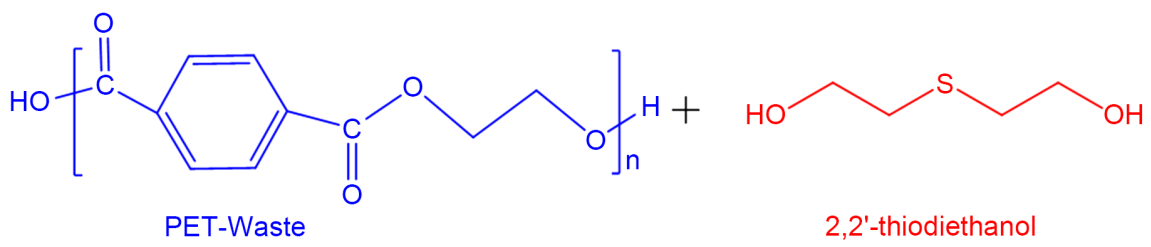<smiles>CC(C)OCCSCCOC(=O)c1ccc(C(=O)OCCSCCC(C)(O)C([18OH])([18OH])[18OH])cc1</smiles>

bis(2-((2-hydroxyethyl)thio)ethyl) terephthalate

Figure 1. Mechanism for preparation of BHET. 


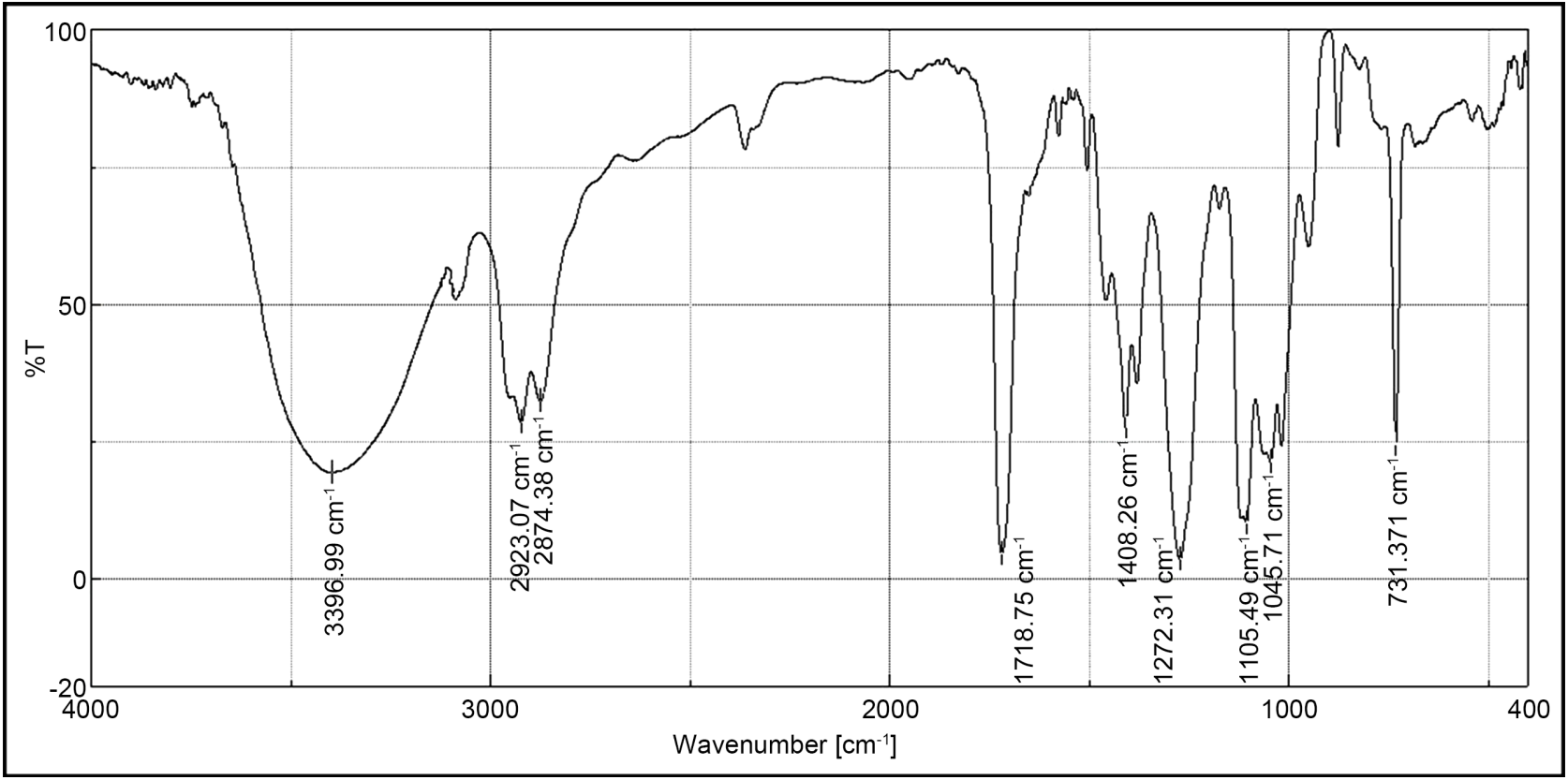

Figure 2. FTIR spectrum of compound BHET.

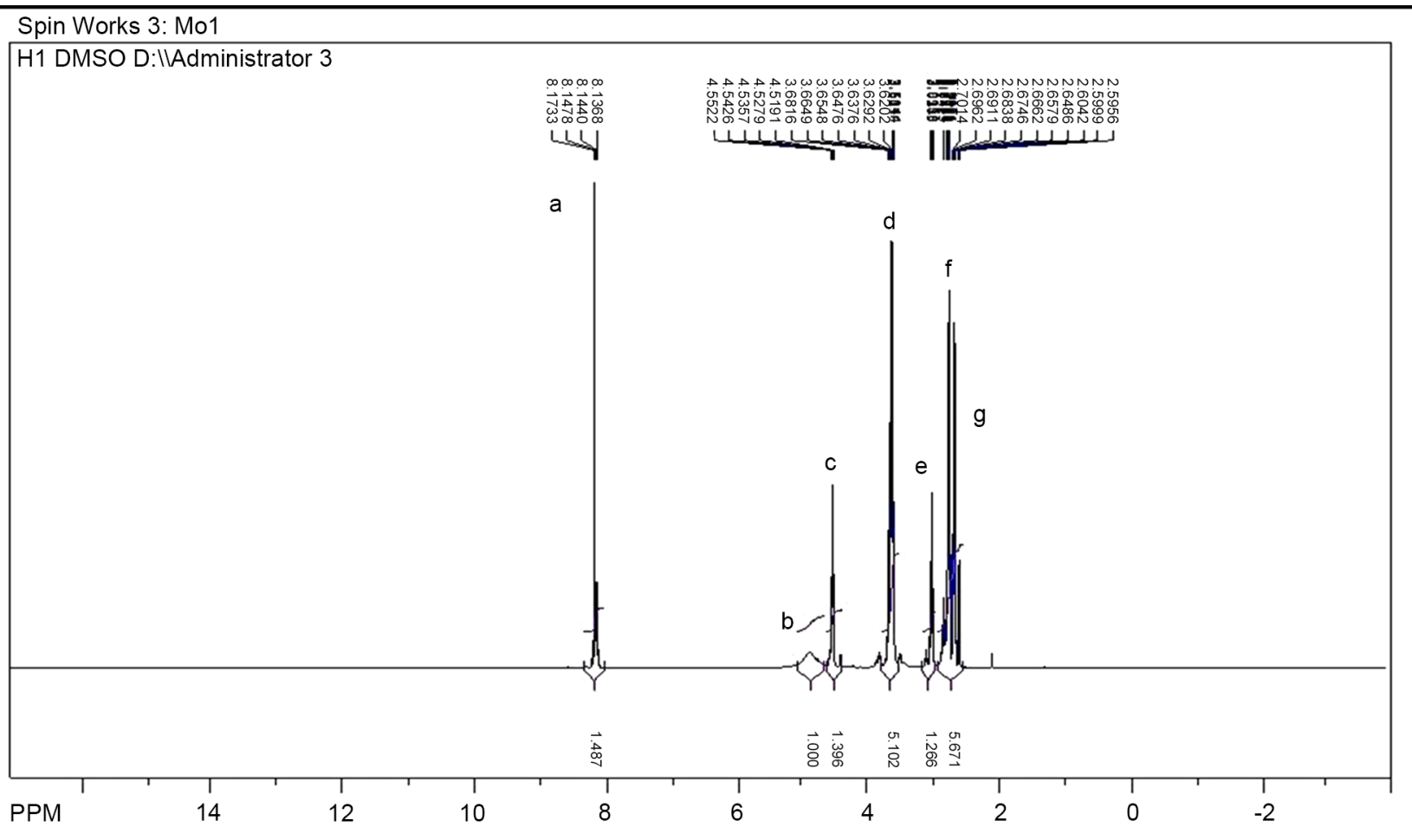

Figure 3. ${ }^{1} \mathrm{HNMR}-$ Spectroscopy for compound BHET.

group of methylene near oxygen atom at $(3.66 \mathrm{ppm})$, and the Triplet (e) peak attributed to the symmetric methylene group nearest to the sulfur atom at $(3.02$ ppm), while the peak (f) at (2.84 ppm) back to the methylene group asymmetric nearest sulfur atom, and the peak at $8.5 \mathrm{ppm}$ is triplet for proton of amide. The peak ( $\mathrm{g})$ at (2.59 $\mathrm{ppm})$ is quintet for solvent ( $\left.\mathrm{d}^{6}-\mathrm{DMSO}\right)$ [17] [18]. 


\section{Results and Discussion}

\subsection{Electrochemical Measurements}

\subsubsection{Polarization Measurements (Tafel Method)}

Typical potentiodynamic polarization curves for the C-steel in $0.1 \mathrm{M} \mathrm{HCl}$ in the presence and absence of different concentrations of BHET are shown in (Figures 4-11) The respective Tafel parameters, inhibition efficiency (\% IE), surface coverage $(\theta)$, corrosion rate and charge transfer resistance are provided in Table 1. It is clear that the shapes of the Tafel plots for the inhibited electrodes are different from those of uninhibited electrodes. The presence of the inhibitor decreases the current density but does not change other aspects of the behavior.

Table 1. Tafel parameters for C-steel $0.1 \mathrm{M} \mathrm{HCl}$ in the absence and presence of different concentrations of BHET at different Temp.

\begin{tabular}{|c|c|c|c|c|c|c|c|c|c|}
\hline $\begin{array}{l}\text { conc. } \\
\text { ppm }\end{array}$ & $\begin{array}{l}\mathrm{T} \\
\mathrm{K}\end{array}$ & $\mathrm{E}_{\text {corr }} \mathrm{mv}$ & $\begin{array}{c}\beta a \\
\mathrm{~A} / \mathrm{V}\end{array}$ & $\begin{array}{c}\beta c \\
A / V\end{array}$ & $\begin{array}{c}\mathrm{I}_{\text {corr }} \\
\mathrm{mA} / \mathrm{cm}^{2}\end{array}$ & $\begin{array}{l}\mathrm{R}_{\mathrm{ct}} \\
\Omega\end{array}$ & $\begin{array}{l}\text { CR } \\
\text { mpy }\end{array}$ & $\% \mathrm{IE}$ & $\theta$ \\
\hline Blank & 298 & -337 & 3.934 & -6.073 & 1.375 & 18.69 & 74.3 & - & - \\
\hline 10 & & -465 & 17.58 & -5.597 & $1.019 \times 10^{-1}$ & 252.2 & 5.5 & 92.5 & 0.925 \\
\hline 20 & & -458 & 14.09 & -5.528 & $7.276 \times 10^{-2}$ & 353.1 & 3.93 & 94.7 & 0.947 \\
\hline 30 & & -471 & 10.59 & -5.636 & $5.811 \times 10^{-2}$ & 442.1 & 3.14 & 95.8 & 0.958 \\
\hline 40 & & -468 & 10.04 & -5.340 & $7.514 \times 10^{-2}$ & 341.9 & 4.06 & 94.5 & 0.945 \\
\hline 50 & & -471 & 9.924 & -5.315 & $6.42 \times 10^{-2}$ & 400.2 & 3.47 & 95.3 & 0.953 \\
\hline Blank & 308 & -523 & 4.574 & -5.954 & 2.117 & 12.14 & 114.41 & - & - \\
\hline 10 & & -477 & 12.69 & -5.361 & $1.961 \times 10^{-1}$ & 130 & 10.6 & 90.7 & 0.907 \\
\hline 20 & & -480 & 11.77 & -4.732 & $2.141 \times 10^{-1}$ & 120 & 11.57 & 90 & 0.900 \\
\hline 30 & & -477 & 11.73 & -5.185 & $9.72 \times 10^{-2}$ & 264.4 & 5.25 & 95.4 & 0.954 \\
\hline 40 & & -468 & 13.1 & -5.465 & $6.024 \times 10^{-2}$ & 426.5 & 3.25 & 97.1 & 0.971 \\
\hline 50 & & -472 & 12.09 & -5.005 & $1.042 \times 10^{-1}$ & 246.5 & 5.63 & 95.0 & 0.950 \\
\hline Blank & 318 & -527 & $8.233 \times 10^{-16}$ & -5.606 & 3.344 & 7.684 & 180.72 & - & - \\
\hline 10 & & -494 & 11.24 & -5.372 & $2.276 \times 10^{-1}$ & 112.9 & 12.3 & 93.2 & 0.932 \\
\hline 20 & & -498 & 10.97 & -5.880 & $3.458 \times 10^{-1}$ & 74.3 & 18.69 & 89.6 & 0.896 \\
\hline 30 & & -494 & 10.2 & -5.798 & $3.244 \times 10^{-1}$ & 79.21 & 17.53 & 90.3 & 0.903 \\
\hline 40 & & -479 & 10.83 & -5.280 & $2.349 \times 10^{-1}$ & 109.4 & 12.69 & 92.3 & 0.923 \\
\hline 50 & & -487 & 10.76 & -5.315 & $2.595 \times 10^{-1}$ & 99 & 14.02 & 92.2 & 0.922 \\
\hline Blank & 328 & -535 & $8.233 \times 10^{-16}$ & $-5.668 \times 10^{-5}$ & 4.709 & 5.456 & 254.52 & - & - \\
\hline 10 & & -523 & 9.531 & -7.472 & $8.090 \times 10^{-1}$ & 31.76 & 43.73 & 82.8 & 0.828 \\
\hline 20 & & -524 & 9.525 & -7.518 & $8.512 \times 10^{-1}$ & 30.19 & 46.01 & 81.9 & 0.819 \\
\hline 30 & & -324 & 8.782 & -6.486 & 1.132 & 22.7 & 61.18 & 75.9 & 0.759 \\
\hline 40 & & -523 & 9.208 & -7.372 & $7.677 \times 10^{-1}$ & 33.47 & 41.48 & 83.6 & 0.836 \\
\hline 50 & & -515 & 9.727 & -8.367 & $6.554 \times 10^{-1}$ & 39.21 & 35.42 & 86.0 & 0.860 \\
\hline
\end{tabular}




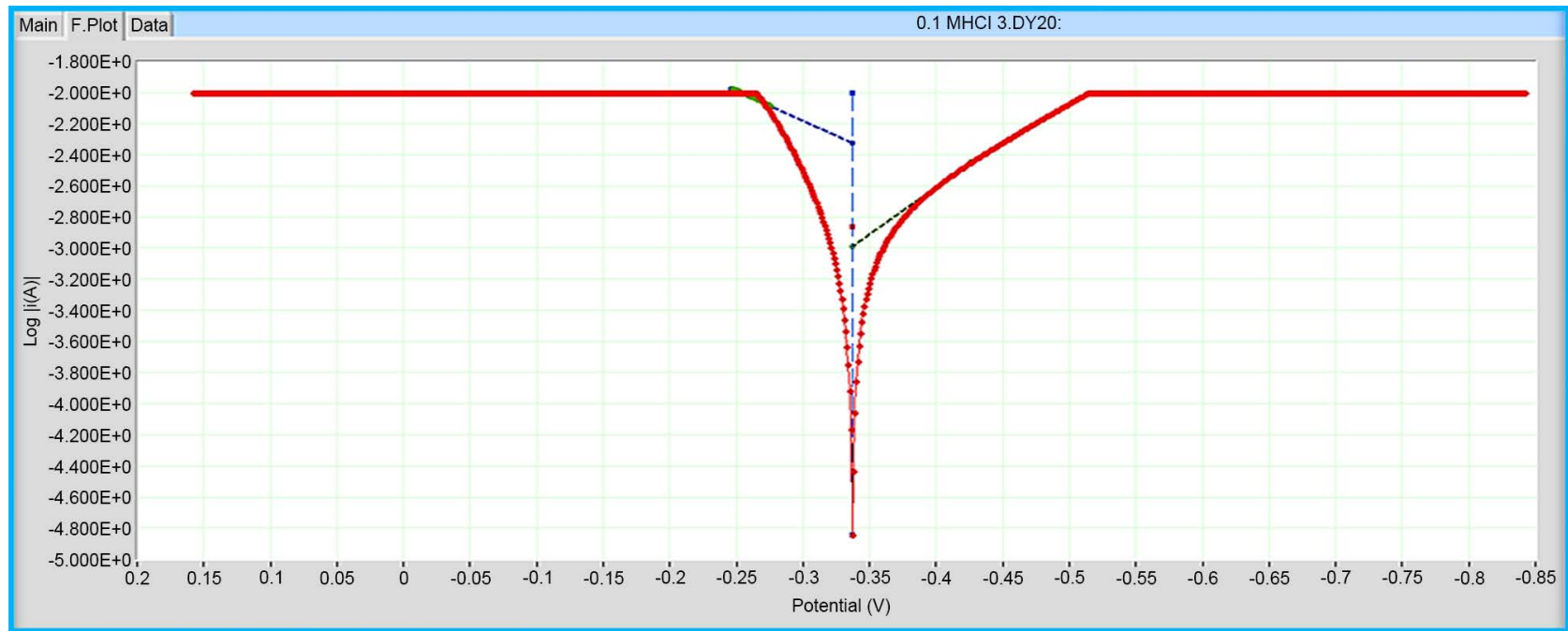

Figure 4. Tafel plots for C-steel at $25^{\circ} \mathrm{C}$ in $0.1 \mathrm{M} \mathrm{HCl}$ (blank).

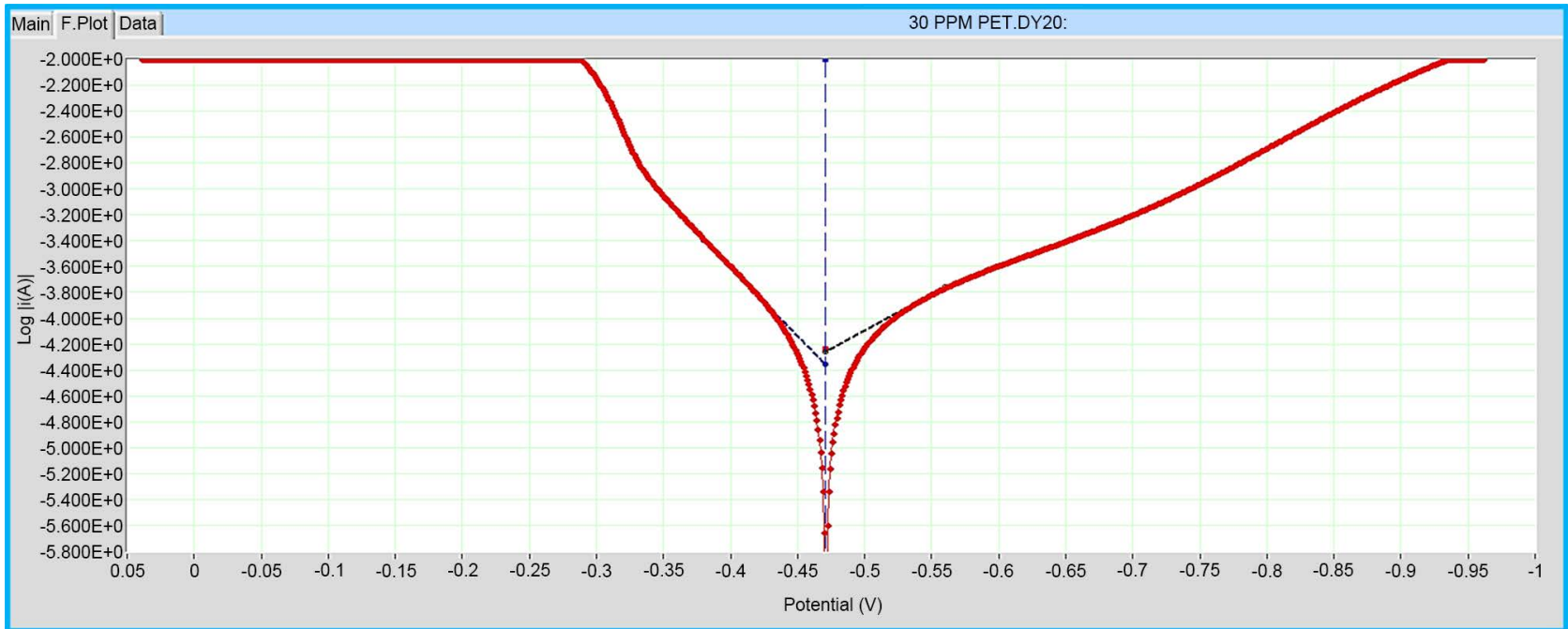

Figure 5. Tafel plots for C-steel at $25^{\circ} \mathrm{C}$ in $30 \mathrm{ppm}$ BHET.

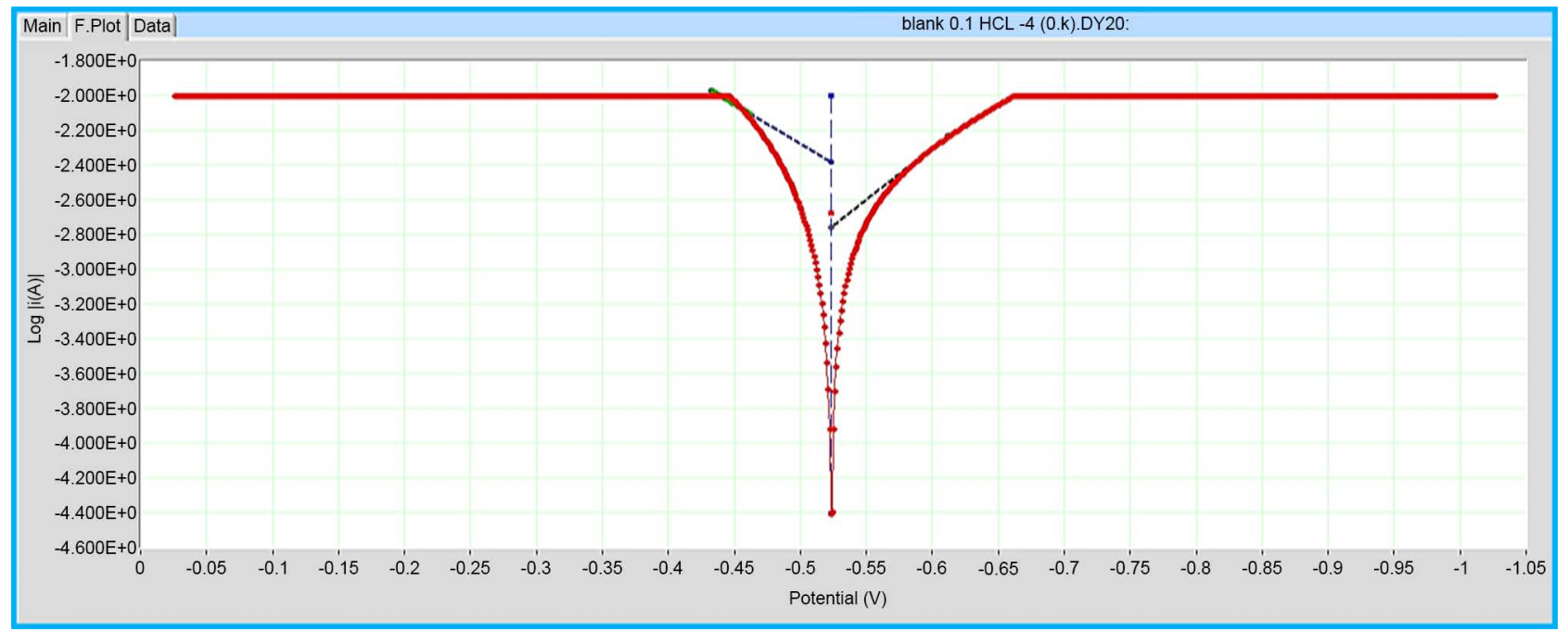

Figure 6. Tafel plots for C-steel at $35^{\circ} \mathrm{C}$ in $0.1 \mathrm{M} \mathrm{HCl}$ (blank). 


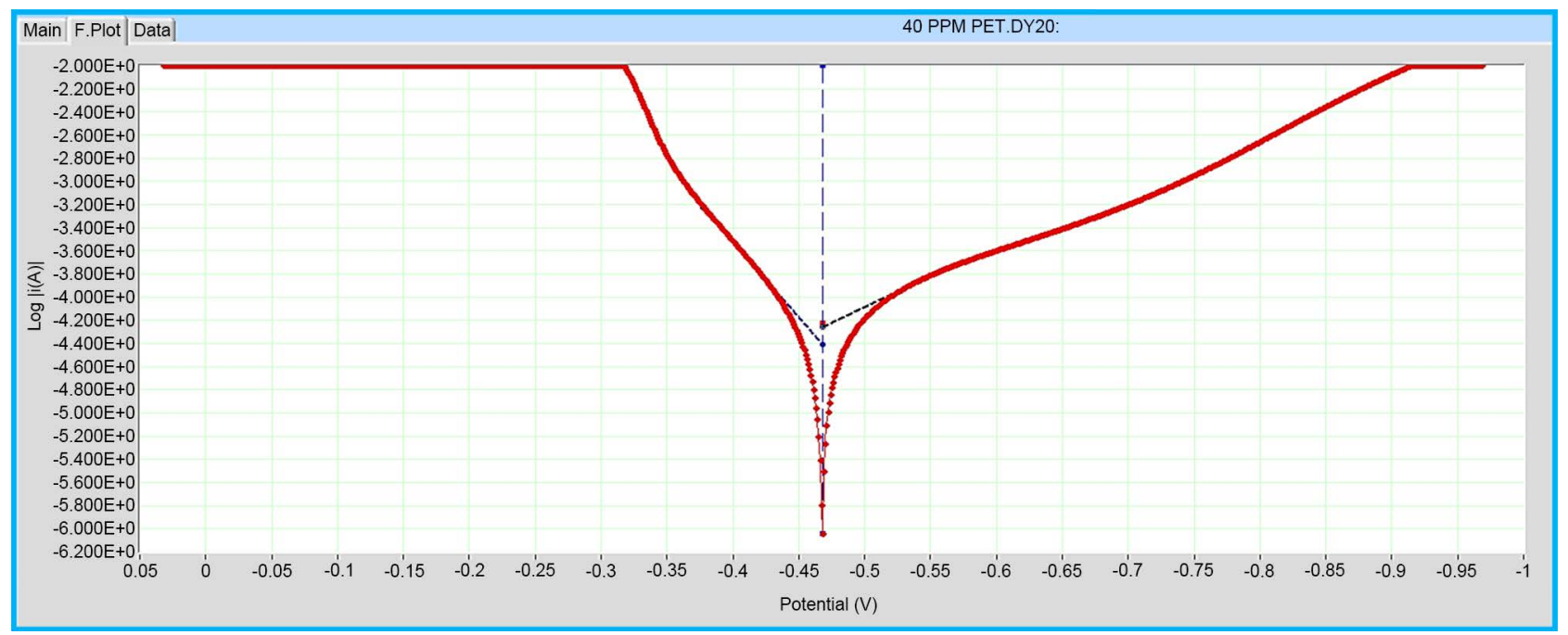

Figure 7. Tafel plots for C-steel at $35^{\circ} \mathrm{C}$ in $40 \mathrm{ppm}$ BHET.

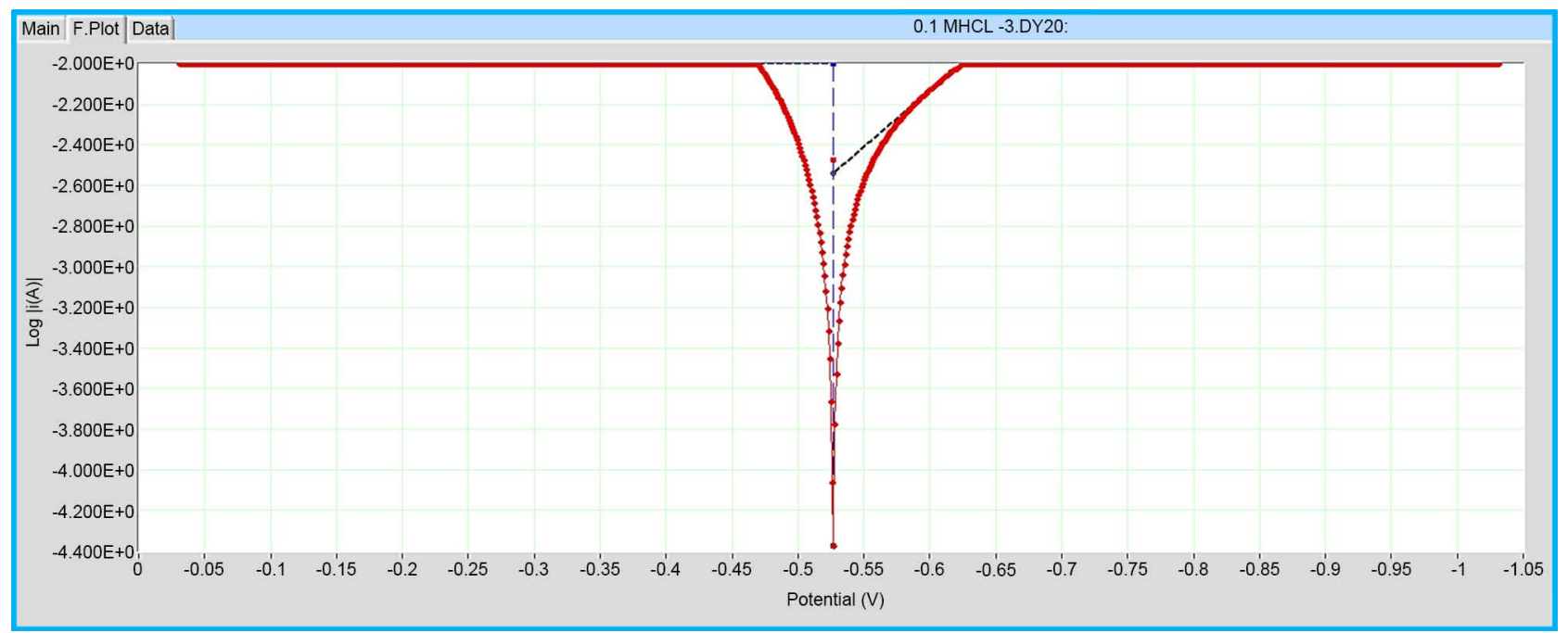

Figure 8. Tafel plots for C-steel at $45^{\circ} \mathrm{C}$ in $0.1 \mathrm{M} \mathrm{HCl}$ (blank).

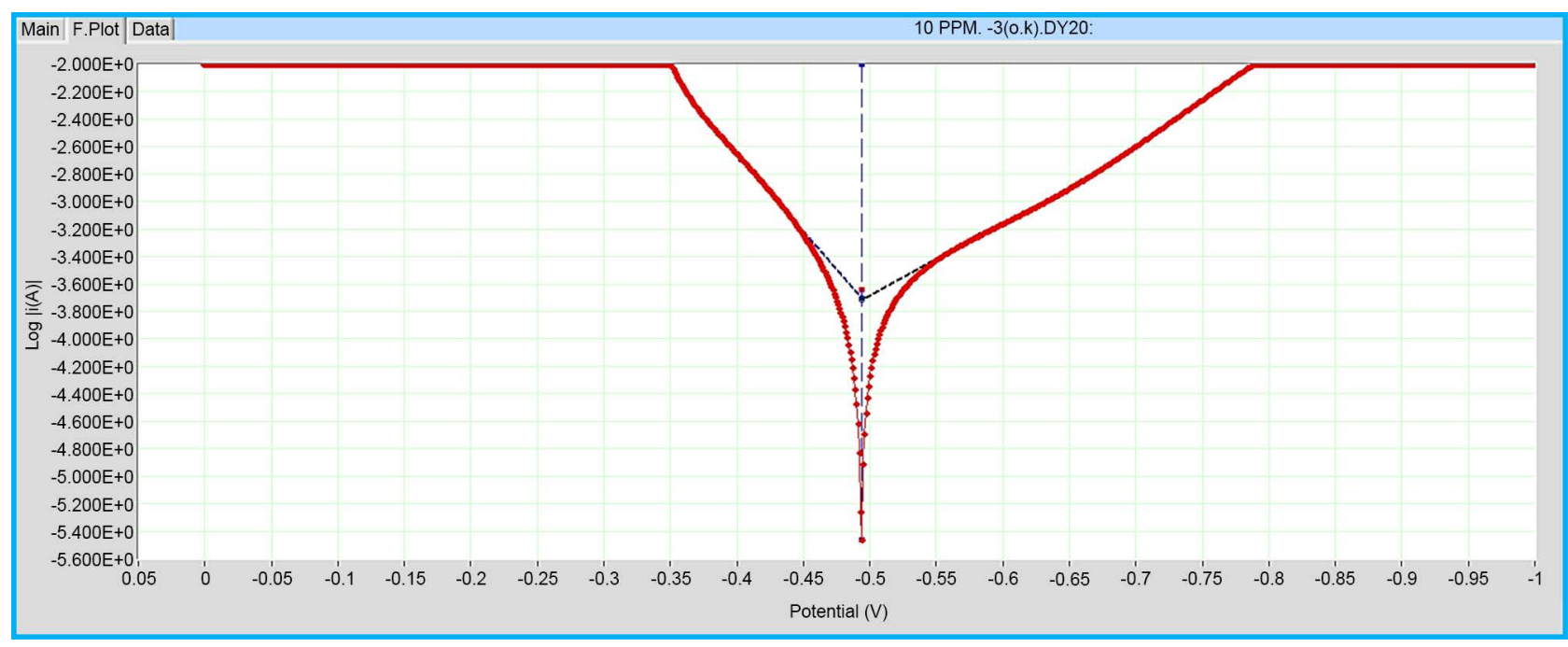

Figure 9. Tafel plots for C-steel at $45^{\circ} \mathrm{C}$ in $10 \mathrm{ppm} \mathrm{BHET}$. 


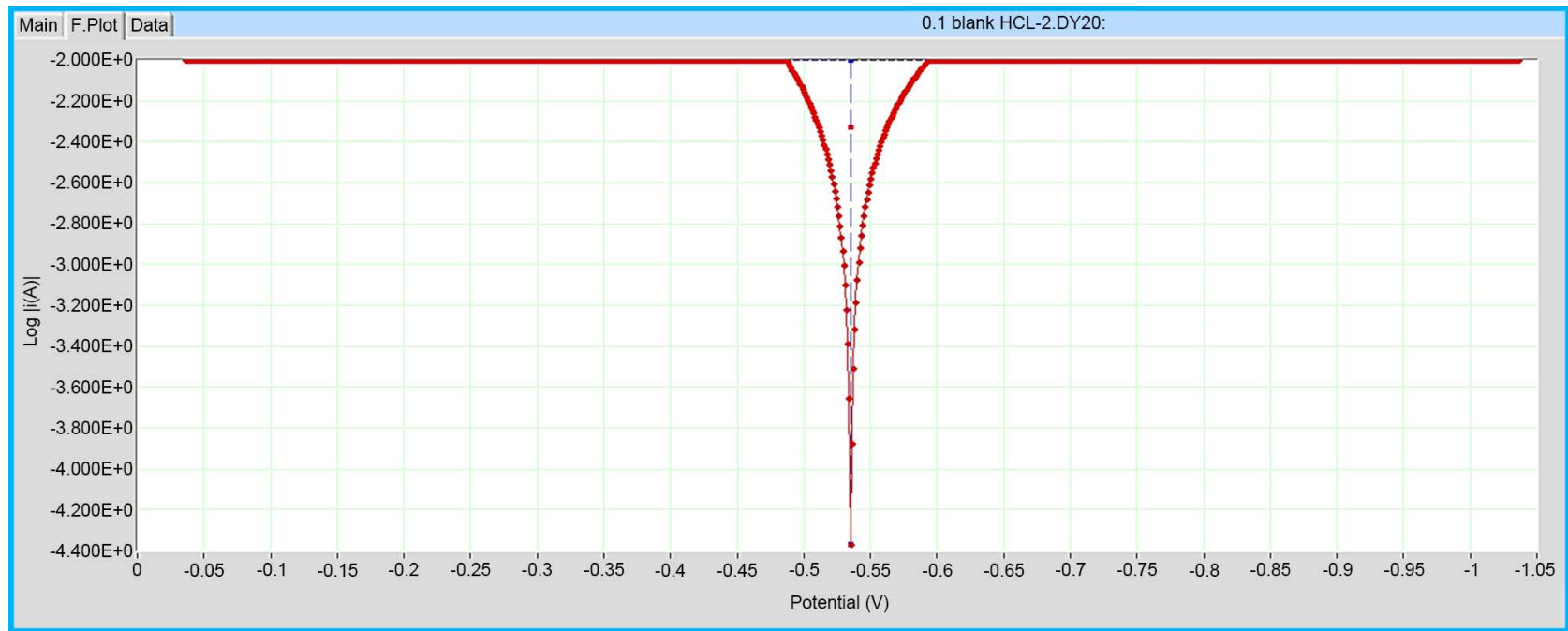

Figure 10. Tafel plots for C-steel at $55^{\circ} \mathrm{C}$ in $0.1 \mathrm{M} \mathrm{HCl}$ (blank).

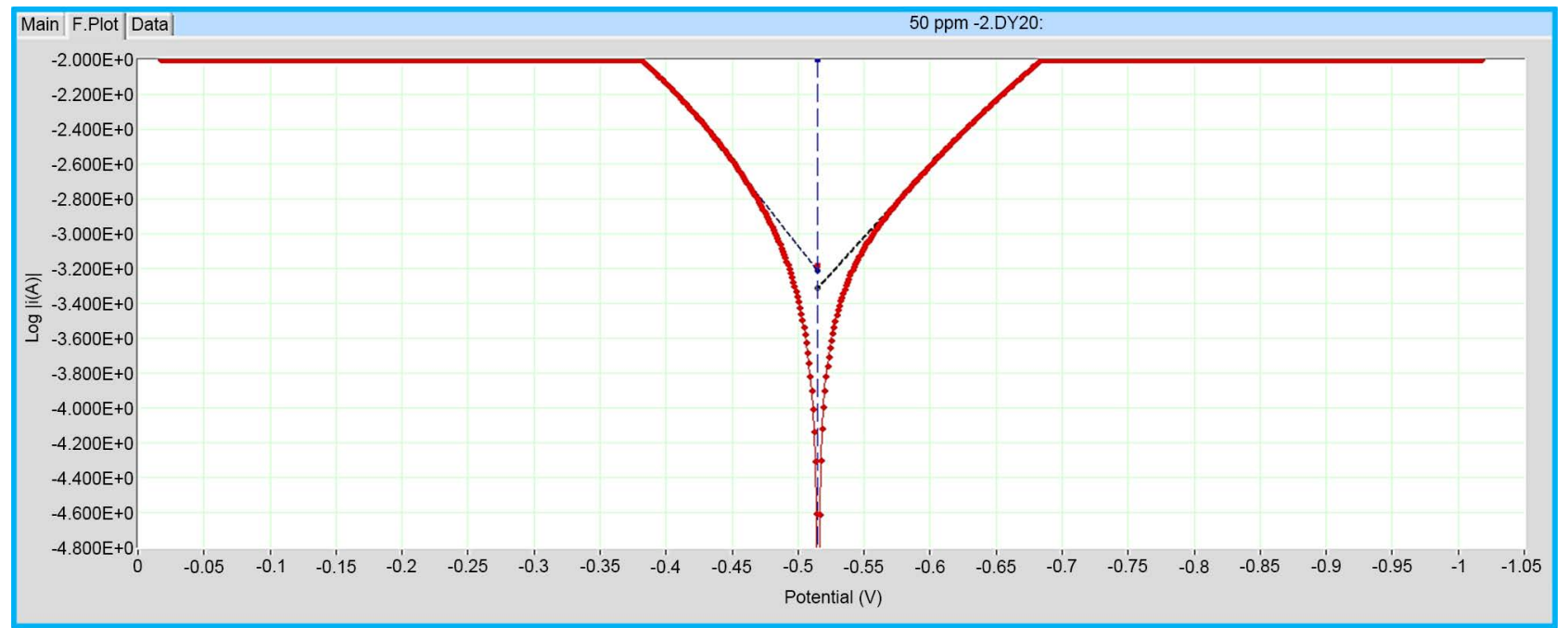

Figure 11. Tafel plots for C-steel at $55^{\circ} \mathrm{C}$ in $40 \mathrm{ppm}$ BHET.

It is evident from Table 1 that the adsorption of the inhibitor shifted the corrosion potential $\left(E_{\text {corr }}\right)$ in the negative direction. The addition of BHET decreases both of the Tafel slopes ( $B a$ and $B C$ ), the anodic and cathodic Tafel slopes. This indicates that BHET is a mixed-type inhibitor affecting the iron dissolution and hydrogen evolution [19] [20]. The reduction of the positive and negative currents in the presence of BHET can be explained by the blocking of active sites by the formation of a protective film on the surface of the electrode [21] [22]. The values of the surface coverage and inhibition efficiency reached its maximum at a BHET concentration of 40 PPM at $298 \mathrm{k}$. As can be seen from Table 1, BHET inhibitor greatly reduces corrosion current with a slight shift in the corrosion potential. If the displacement in the corrosion potential is more than $85 \mathrm{mV}$, with respect to the corrosion potential of the blank solution, the inhibitor can be designated as a cathodic or anodic type [22]. In the present study, and through the difference corrosion potential values of corrosion inhibitor in the presence 
or absence of the inhibitor, which indicated that the studied inhibitor is a mixedtype inhibitor which is in agreement with some other studies [20].

Table 1 shows the values of (Rct) increases with inhibitor, and the value of Rct indicates that of the efficiency inhibitor to preventing the erosion of carbonsteel in the acidic media. The highest resistance to charge transfer $\left(\mathrm{R}_{\mathrm{ct}(\mathrm{inh} \cdot)}\right)$ value at $(298 \mathrm{~K})$ and was $(442.1 \Omega)$ at a concentration $(30 \mathrm{ppm})$ of the inhibitor. Using BHET inhibitor at $(328 \mathrm{~K})$ gave the highest value of $\left(\mathrm{R}_{\mathrm{ct}(\mathrm{inh} \cdot)}\right)$ of $39.21 \Omega$ at a concentration (50 ppm), while the value reached to $5.456 \Omega$ in the absence of inhibitor at the same conditions [23].

\subsubsection{Effect of Temperature}

Temperature is an important parameter when studying metal dissolution. It is known that the effect of temperature on the acid-metal reaction is highly complex. The corrosion rate in acid solutions, for example, increases exponentially with an increasing temperature because hydrogen evolution decreases. Many changes may occur on the metal surface, such as adsorption, desorption, rearrangement or decomposition of the inhibitor [24], Only a few inhibitors are effective at high temperature as they are at low temperature [25].

The effect of increasing temperature (from 298 - $328 \mathrm{~K}$ ) on the corrosion rate of C-steel in $0.1 \mathrm{M} \mathrm{HCl}$, and its effects on inhibition action of $30 \mathrm{ppm}$ BHET are shown in Table 2. The inhibitory effect (\% IE) decreased from $97.1 \%$ at $308 \mathrm{~K}$ to $75.9 \%$ at $328 \mathrm{~K}$.

The values of the activation energy Ea of the corrosion process in $0.1 \mathrm{M} \mathrm{HCl}$ in the presence and absence of BHET was calculated using the Arrhenius equation: [26]

$$
\ln \mathrm{W}=\ln \mathrm{A}-\frac{\mathrm{Ea}}{\mathrm{RT}}
$$

where $\mathrm{W}$ is the corrosion rate (mpy), $\mathrm{A}$ is the Arrhenius constant, Ea is the activation energy, $\mathrm{R}$ is the gas constant and $\mathrm{T}$ is the absolute temperature.

Figure 12 shows Arrhenius plots of the $\ln$ CR vs 1/T for carbon steel in the corrosive medium with and without addition of $30 \mathrm{ppm}$ of BHET. Straight lines are obtained with a slope of $(-\mathrm{Ea} / \mathrm{R})$. The value of Ea can be obtained from the slope of the straight line which was found to be $0.0337 \mathrm{~kJ} \cdot \mathrm{mol}^{-1}$ and 0.0619 $\mathrm{kJ} \cdot \mathrm{mol}^{-1}$ in the absence and presence of $30 \mathrm{ppm}$ of BHET, respectively. The

Table 2. The effect of temperature on the corrosion rates of C-steel in the absence and presence of $30 \mathrm{ppm}$ of BHET.

\begin{tabular}{ccccc}
\hline $\mathrm{T}\left({ }^{\circ} \mathrm{C}\right)$ & $\begin{array}{c}0.1 \mathrm{M} \mathrm{HCl} \\
\mathrm{CR}(\mathrm{mpy})\end{array}$ & $\begin{array}{c}\text { BHET } \\
\mathrm{CR}(\mathrm{mpy})\end{array}$ & $\%$ IE & $\theta$ \\
\hline 25 & 74.3 & 3.14 & 95.8 & 0.958 \\
35 & 114.41 & 5.25 & 95.4 & 0.954 \\
45 & 180.72 & 17.53 & 90.3 & 0.903 \\
55 & 254.52 & 61.18 & 75.9 & 0.759 \\
\hline
\end{tabular}


higher value of $\mathrm{Ea}$ in the presence of BHET than its absence indicates a strong inhibitive action of the BHET by increasing the energy barrier for the corrosion process [27]. And the higher Ea value in the inhibited solution can be correlated with the increased thickness of the double layer.

A plot of $\ln (\mathrm{W})$ against 1/T shown in Figure 13 which gives straight lines with a slope of $(-\Delta \mathrm{H} / \mathrm{R})$ and an intercept of $[(\ln (\mathrm{R} / \mathrm{Nh}))+(\Delta \mathrm{S} / \mathrm{R})]$ to which the values of $\Delta \mathrm{H}$ and $\Delta \mathrm{S}$ are calculated and are given in Table 3.

The enthalpy and entropy of activation $(\Delta \mathrm{H}$ and $\Delta \mathrm{S})$ can be calculated by given equation:

$$
\ln \frac{\mathrm{W}}{\mathrm{T}}=\ln \mathrm{A} \frac{\mathrm{R}}{\mathrm{Nh}}+\frac{\Delta \mathrm{S}}{\mathrm{R}}-\frac{\mathrm{SH}}{\mathrm{RT}}
$$

where h is Plank constant and $\mathrm{N}$ is Avogadro's number.

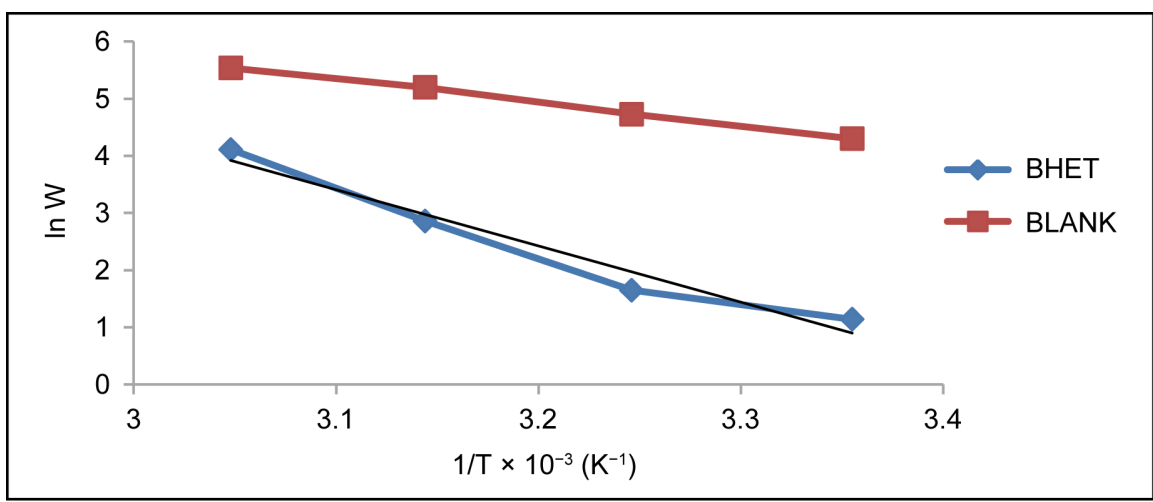

Figure 12. Arrhenius plots for C-steel in $0.1 \mathrm{MHCl}$ in the presence and absence of BHET (30 ppm).

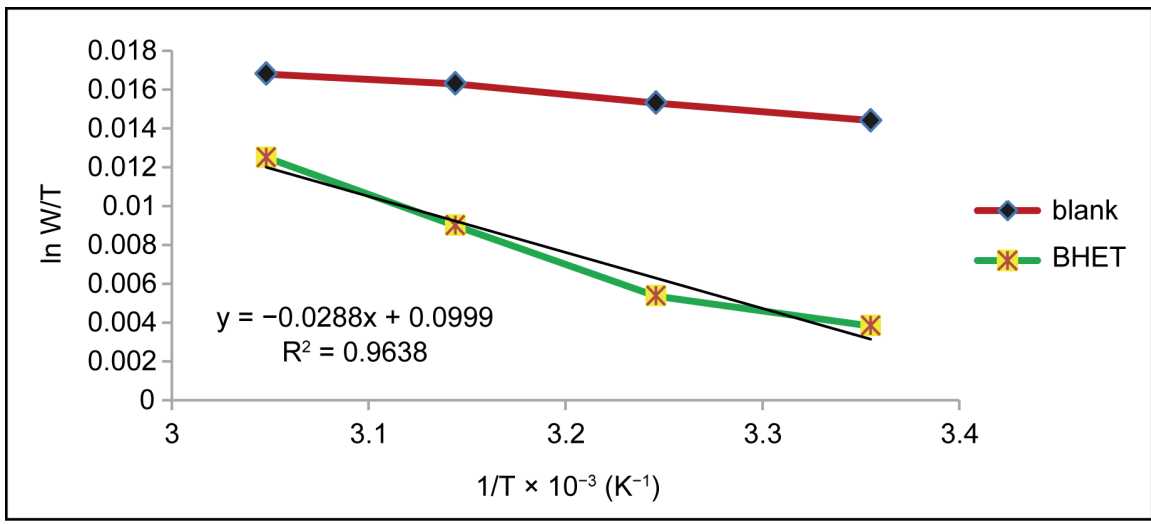

Figure 13. Transition-state plots of $\ln (\mathrm{W} / \mathrm{T})$ versus $1 / \mathrm{T}$ in $0.1 \mathrm{M} \mathrm{HCl}$ in absence and presence of various concentrations of BHET.

Table 3. Thermodynamic parameters for mild steel in $0.1 \mathrm{M} \mathrm{HCl}$ in absence and presence of BHET.

\begin{tabular}{cccc}
\hline Inhibitor con. (ppm) & $\mathrm{Ea}\left(\mathrm{kJmol}^{-1}\right)$ & $\Delta \mathrm{H}\left(\mathrm{kJmol}^{-1}\right)$ & $\Delta \mathrm{S}\left(\mathrm{KJmol}^{-1} \cdot \mathrm{K}^{-1}\right)$ \\
\hline 0 (BLANK) & 0.0337 & 0.0705 & -0.19685 \\
30 & 0.0619 & 0.1818 & -0.19636 \\
\hline
\end{tabular}


The positive signs of enthalpies $(\Delta \mathrm{H})$ reflect the endothermic nature of dissolution process [28] [29]. Large and negative values of entropies $(\Delta S)$ show that the activated complex in the rate determining step represents an association rather than a dissociation step, meaning that a decrease in disordering takes place on going from reactants to the activated complex.

\subsection{Adsorption Isotherm}

Adsorption isotherms are very important to understand the mechanism of inhibition corrosion reactions. The electrochemical processes on the metal surface which related to the adsorption of the inhibitor [30] and the adsorption depend on the chemical structure of the inhibitor. The adsorption of the inhibitor molecules from aqueous solutions can be regarded as quasi substitution process [31] [32] [33] between the organic compound in the aqueous phase and water molecules at the electrode surface. By examining the degree of surface coverage $(\theta)$ which determined by potentiodynamic polarization technique to various isotherms. The best isotherm obtained was Langmuir's adsorption isotherm.

The Langmuir adsorption isotherm may be written in the following form:

$$
\mathrm{K}_{\mathrm{ads}}=\frac{\theta}{(1-\theta) \mathrm{C}}
$$

where $\mathrm{C}$ is the concentration of inhibitor, $\mathrm{K}_{\mathrm{ads}}$ the adsorptive equilibrium constant, and $\theta$ is the fraction of the surface covered calculated as follows:

$$
\theta=\mathrm{E}(\%) / 100
$$

The adsorptive equilibrium constant $\left(\mathrm{K}_{\mathrm{ads}}\right)$ is related to the standard free energy of adsorption reaction $\left(\Delta \mathrm{G}_{\mathrm{ads}}^{0}\right)$ as shown the following equation [34]:

$$
\Delta \mathrm{G}_{\mathrm{ads}}^{0}=-\mathrm{RT} \ln 55.5 \mathrm{~K}_{\mathrm{ads}}
$$

$\mathrm{R}$ is the universal gas constant, $\mathrm{T}$ is the absolute temperature $(\mathrm{K})$ and the value of 55.5 is the concentration of water in the solution in $\mathrm{mol} / \mathrm{L}$. These parameters are shown the Table 4 . The obtained results are clearly shows that the data fit well with Langmuir adsorption isotherm.

Large values of $\mathrm{K}_{\mathrm{ads}}$ mean good inhibition efficiency of the inhibitor and strong electrical interaction between the adsorbate and the adsorbent.

Table 4. Equilibrium constant $\left(\mathrm{K}_{\mathrm{ads}}\right)$, adsorption free energy $\left(\Delta \mathrm{G}_{\mathrm{ads}}^{0}\right)$ for the adsorption of inhibitors on C-steel in $0.1 \mathrm{M} \mathrm{HCl}$ at $(298 \mathrm{k})$.

\begin{tabular}{ccccc}
\hline $\begin{array}{c}\text { conc. } \\
\mathrm{ppm}\end{array}$ & $\begin{array}{c}\mathrm{T} . \\
\mathrm{k}\end{array}$ & $\theta$ & $\begin{array}{c}\Delta \mathrm{G}_{\text {ads }}^{0} \\
(\mathrm{KJ} / \mathrm{mol})\end{array}$ & $\begin{array}{c}\mathrm{K}_{\mathrm{ads}} \\
\mathrm{L} / \mathrm{g}\end{array}$ \\
\hline 10 & & 0.925 & -27.537 & 1.233 \\
20 & & 0.947 & -26.740 & 0.893 \\
30 & 298 & 0.958 & -26.340 & 0.760 \\
40 & & 0.945 & -24.926 & 0.429 \\
50 & & 0.953 & -24.785 & 0.405 \\
\hline
\end{tabular}


The negative values of $\Delta \mathrm{G}_{\mathrm{ads}}^{0}$ indicate that the adsorption of inhibitor molecule on steel surface is spontaneous and also the strong interaction between inhibitor molecules and the metal surface [35] [36] [37]. Generally, an adsorption process suggests either physisorption or chemisorption. $\Delta \mathrm{G}_{\text {ads }}^{0}$ value lower than $(-40 \mathrm{~kJ} / \mathrm{mol})$ are related to the chemisorption between charged molecule and charged metal [38] [39].

In the present work, the value of $\Delta \mathrm{G}_{\mathrm{ads}}$ is found to be lower than $(-40 \mathrm{~kJ} / \mathrm{mol})$; means that the adsorption mechanism of BHET on carbon steel surface is mainly the chemisorption.

\section{Study Thermal Analysis TGA \& DTA for Inhibitor BHET}

Was conducted thermal analysis of inhibitor above the rate of heating $\left(10^{\circ} \mathrm{C} / \mathrm{min}\right)$ and the presence of an inert atmosphere of nitrogen has been extracting some thermal functions of analysis, thermal analysis curve TGA \& DTA (Figure 14) and note the Table 5 inhibitor polymer BHET find that inhibitors polymer mentioned stable thermally and up to a temperature $\left(250^{\circ} \mathrm{C}\right)$, and also that we find $\left(\mathrm{T}_{\max }\right)$ (Temperature Decomposition) at $\left(341^{\circ} \mathrm{C}\right)$ which is a relatively high degree of heat, while Rate Decomposition is 4.22 When you reach the degree of dissociation temperature $50 \mathrm{wt} \%$ loss at $\left(336^{\circ} \mathrm{C}\right)$, While the (Chair yield) at $\left(600^{\circ} \mathrm{C}\right)$ where the compound residual rate of up to $6 \%$, also notes the remaining ratio the compound at a temperature of disintegration of the initial temperature $\left(\mathrm{T}_{\mathrm{i}}=\right.$ $\left.276^{\circ} \mathrm{C}\right)$ was $95 \%$, and when the final disintegration temperature $\left(\mathrm{T}_{\mathrm{f}}=406^{\circ} \mathrm{C}\right)$ was $9.9 \%$, while the value of the difference between the thermal two degrees $\Delta \mathrm{T}$ is

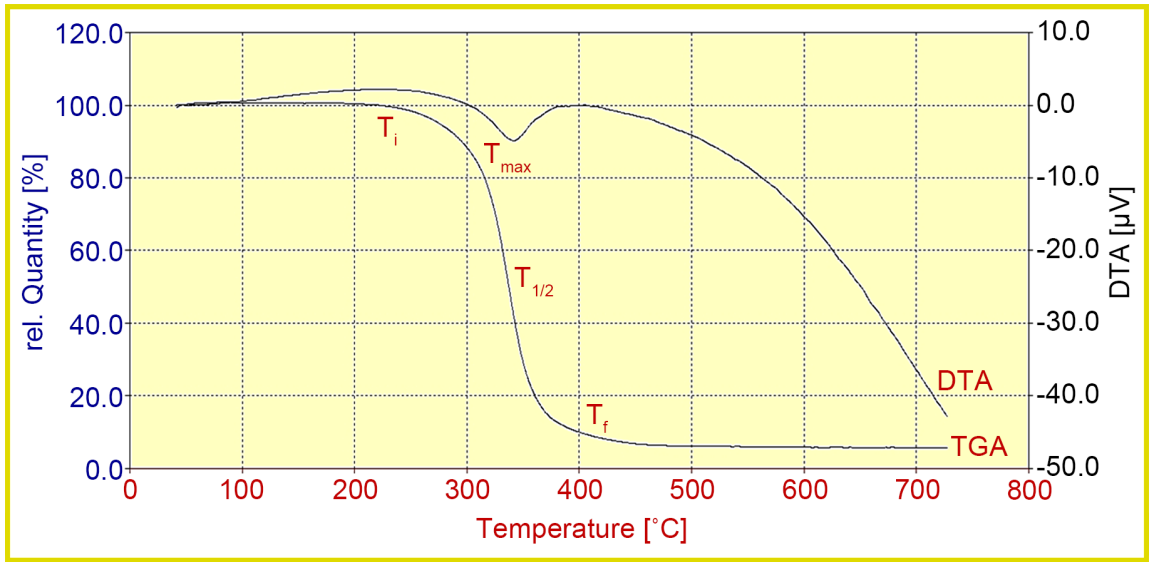

Figure 14. The thermal analysis, TGA and DTA inhibitor BHET.

Table 5. The functions of thermal analysis TGA and DTA of BHET.

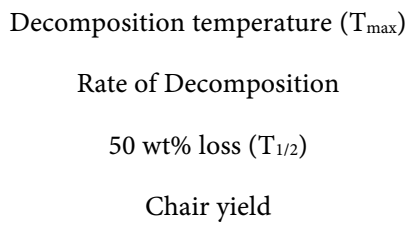

\section{$341^{\circ} \mathrm{C}$}

4.22

$336^{\circ} \mathrm{C}$

$6 \%$ at $600^{\circ} \mathrm{C}$

$130^{\circ} \mathrm{C}$ 
$130^{\circ} \mathrm{C}$, Note note from the form of peak of the technology curve DTA find that kind of interaction Endo thermal [40] [41] [42].

\section{Conclusion}

(Bis(2-((2-hydroxyethyl)thio)ethyl) terephthalate (BHET) act as corrosion inhibitors of carbon steel in $0.1 \mathrm{M} \mathrm{HCl}$ solutions. The inhibition efficiency increases with increase in inhibitors concentrations and decreases with raising temperature. The adsorption of the investigated compounds follows the Langmuir's adsorption isotherm. The investigated compounds were mixed type inhibitors. The adsorption of the investigated compound on carbon steel surface in $\mathrm{HCl}$ solution follows Langmuir adsorption isotherm. The negative values of $\Delta \mathrm{G}_{\text {ads }}^{0}$ show the spontaneity of the adsorption process. The parameter of adsorption free activation energy $\Delta \mathrm{G}_{\mathrm{ads}}^{0}$ indicates that the adsorption of inhibitor involves chemisorption.

\section{References}

[1] Colomines, G., Robin, J. and Tersac, G. (2005) Study of the Glycolysis of PET by Oligoesters. Polymer, 46, 3230-3247. https://doi.org/10.1016/j.polymer.2005.02.047

[2] Achilias, D.S., Roupakias, C., Megalokonomos, P., Lappas, A.A. and Antonakou, E.V. (2007) Chemical Recycling of Plastic Wastes Made from Polyethylene (LDPE and HDPE) and Polypropylene (PP). Journal of Hazardous Materials, 149, 536-542.

[3] Achilias, D.S. (2007) Chemical Recycling of Poly(Methyl Methacrylate) by Pyrolysis. Potential use of the Liquid Fraction as a Raw Material for the Reproduction of the Polymer. European Polymer Journal, 43, 2564-2575.

[4] Al-Salem, S.M., Lettieri, P. and Baeyens, J. (2009) Recycling and Recovery Routes of Plastic Solid Waste (PSW): A Review. Waste Management, 29, 2625-2643.

[5] Chilton, T., Burnley, S. and Nesaratnam, S. (2010) A Life Cycle Assessment of the Closed-Loop Recycling and Thermal Recovery of Post-Consumer PET. Resources, Conservation and Recycling, 54, 1241-1249. https://doi.org/10.1016/j.resconrec.2010.04.002

[6] Dullius, J., Ruecker, C., Oliveira, V., Ligabue, R. and Einloft, S. (2006) Chemical Recycling of Post-Consumer PET: Alkyd Resins Synthesis. Progress in Organic Coatings, 57, 123-127. https://doi.org/10.1016/j.porgcoat.2006.07.004

[7] Osaka, O. and Shiga, S. (2009) Converting Waste Plastics into a Resource. International Environmental Technology Centre (IETC), Report.

[8] Kaesche, H. (2003) Corrosion of Metals Physicochemical Principles and Current Problems. Chapter 1, Springer.

[9] Valipour, M., Shekarchi, M. and Ghods, P. (2014) Comparative Studies of Experimental and Numerical Techniques in Measurement of Corrosion Rate and Time-toCorrosion-Initiation of Rebar in Concrete in Marine Environments. Cement \& Concrete Composites, 48, 98-107.

https://doi.org/10.1016/j.cemconcomp.2013.11.001

[10] Kim, J., Park, S. and Moon, I. (2009) Corrosion Control Document Database System in Refinery Industry. Chemical Engineering, 27, 1839-1844.

[11] Wu, W., Liu, Z. and Krys, D. (2012) Improving Laser Image Resolution for Pitting Corrosion Measurement Using Markov Random Field Method. Automation in Construction, 21, 172-183. https://doi.org/10.1016/j.autcon.2011.06.002 
[12] Alvarez-Pampliega, A., Hauffman, T., Petrova, M., Breugelmansa, T., Muselle, T., Van den Bergh, K., De Strycker, J., Terryn, H. and Hubin, A. (2014) Corrosion Study on Al-Rich Metal-Coated Steel by Odd Random Phase Multisine Electrochemical Impedance Spectroscopy. Electrochimica Acta, 124, 165-175. https://doi.org/10.1016/j.electacta.2013.09.159

[13] Al Juhaiman, L.A. (2016) Polyvinyl Pyrrolidone as a Corrosion Inhibitor for Carbon Steel in HCl. International Journal of Electrochemical Science, 11, 2247-2262.

[14] El-Hameed, R.S.A. (2011) Aminolysis of Polyethylene Terephthalate Waste as Corrosion Inhibitor for Carbon Steel in $\mathrm{HCl}$ Corrosive Medium. Advances in Applied Science Research, 2, 483-499.

[15] Singh, A., Singh, V.K. and Quraishi, A. (2010) Aqueous Extract of Kalmegh (Andrographis paniculata) Leaves as Green Inhibitor for Mild Steel in Hydrochloric Acid Solution. International Journal of Corrosion, 2010, Article ID: 275983.

[16] Silverstien, M., Webster, F.X. and Kiemle, D.J. (2005) Spectrometric Identification of Organic Compounds. John Wiley \& Sons, Inc., New York.

[17] Gauglitz, G. and Vo-Dinh, T. (2003) Handbook of Spectroscopy. WILEY-VCH Verlag GmbH \& Co. KGaA, Weinheim. https://doi.org/10.1002/3527602305

[18] Mistry B.D. (2009) Handbook of Spectroscopic Data: Chemistry. Oxford Book Company, Jaipur.

[19] Shukla, K.S. and Quraishi, M.A. (2009) Cefotaxime Sodium: A New and Efficient Corrosion Inhibitor for Mild Steel in Hydrochloric Acid Solution. Corrosion Science, 51, 1007-1011. https://doi.org/10.1016/j.corsci.2009.02.024

[20] Singh, A.K., Singh, A.K. and Ebenso, E.E. (2014) Inhibition Effect of Cefradine on Corrosion of Mild Steel in $\mathrm{HCl}$ Solution. International Journal of Electrochemical Science, 9, 352-364.

[21] Yurt, A., Balaban, A., Kandemir, S.U., Bereket, G. and Erk, B. (2004) Investigation on Some Schiff Bases as $\mathrm{HCl}$ Corrosion Inhibitors for Carbon Steel. Materials Chemistry and Physics, 85, 420-426. https://doi.org/10.1016/j.matchemphys.2004.01.033

[22] Uhlig, H.H. (1971) Corrosion and Corrosion Control. 2nd Edition, John Wiley and sons Inc., Hoboken.

[23] Lantsoght, E.O.L., van der Veen, C. and de Boer, A. (2016) Improved Formulation for Compressive Fatigue Strength of Concrete. In: Beushausen, H.D., Alexander, M.G., Dehn, F. and Moyo, P., Eds., Proceedings of the 4th International Conference on Concrete Repair, Rehabilitation and Retrofitting (ICCRRR-4), Taylor \& Francis Group, London, 1011-1018.

[24] Zerga, B., Hammouti, B., Touhami, M.E., Touir, R., Taleb, M., Sfaira, M., Bennajeh, M. and Forssal, I. (2012) Comparative Inhibition Study of New Synthesised Pyridazine Derivatives towards Mild Steel Corrosion in Hydrochloric Acid. Part-II: Thermodynamic Proprieties. International Journal of Electrochemical Science, 7, 471-483.

[25] Shalabi, K., Abdallah, Y.M., Hassan, H.M. and Fouda, A.S. (2014) Adsorption and Corrosion Inhibition of Atropa Belladonna Extract on Carbon Steel in $1 \mathrm{M} \mathrm{HCl} \mathrm{So-}$ lution. International Journal of Electrochemical Science, 9, 1468-1487.

[26] Bhat, J. and Alva, V. (2009) Corrosion Inhibition of Aluminium by 2-Chloronicotinic Acid in HCl Medium. Indian Journal of Chemical Technology, 16, 228-233.

[27] Solmaz, R., Kardas, G., Yazic1, B. and Erbil, M. (2008) Adsorption and Corrosion Inhibitive Properties of 2-Amino-5-Mercapto-1,3,4-Thiadiazole on Mild Steel in Hydrochloric Acid Media. Colloids and Surfaces A: Physicochemical and Engineering Aspects, 312, 7-17. https://doi.org/10.1016/j.colsurfa.2007.06.035 
[28] Tao, Z., Hea, W., Wang, S., Zhang, S. and Zhou, G. (2012) A Study of Differential Polarization Curves and Thermodynamic Properties for Mild Steel in Acidic Solution with Nitrophenyltriazole Derivative. Corrosion Science, 60, 205-213. https://doi.org/10.1016/j.corsci.2012.03.035

[29] Yadav, D.K., Maiti, B. and Quraishi, M.A. (2010) Electrochemical and Quantum Chemical Studies of 3,4-Dihydropyrimidin-2(1H)-Ones as Corrosion Inhibitors for Mild Steel in Hydrochloric Acid Solution. Corrosion Science, 52, 3586-3598. https://doi.org/10.1016/j.corsci.2010.06.030

[30] Hackerman, N. (1962) Recent Advances in Understanding of Organic Inhibitors. Corrosion, 18, 332t-337t. https://doi.org/10.5006/0010-9312-18.9.332

[31] Ateya, B.G., El-Anadouli, B.E. and El-Nizamy, F.M. (1984) The Effect of Thiourea on the Corrosion Kinetics of Mild Steel in $\mathrm{H}_{2} \mathrm{SO}_{4}$. Corrosion Science, 24, 497-507. https://doi.org/10.1016/0010-938X(84)90032-5

[32] Babic-Samardzija, K., Lupu, C., Hackerman, N., Barron, A.R. and Luttge, A. (2005) Inhibitive Properties and Surface Morphology of a Group of Heterocyclic Diazoles as Inhibitors for Acidic Iron Corrosion. Langmuir, 21, 12187-12196. https://doi.org/10.1021/la0517661

[33] Bouayed, M., Rabaa, H., Srhiri, A., Saillard, J.Y., Bachir, A.B. and Beuze, L.A. (1999) Experimental and Theoretical Study of Organic Corrosion Inhibitors on Iron in Acidic Medium. Corrosion Science, 41, 501-517. https://doi.org/10.1016/S0010-938X(98)00133-4

[34] Mansfeld, F., Kending, M.W. and Tsai, S. (1982) Recording and Analysis of AC Impedance Data for Corrosion Studies. Corrosion, 37, 301-307. https://doi.org/10.5006/1.3621688

[35] Benali, O., Larabi, L., Tabti, B. and Harek, Y. (2005) Influence of 1-Methyl 2-Mercapto Imidazole on Corrosion Inhibition of Carbon Steel in $0.5 \mathrm{M} \mathrm{H}_{2} \mathrm{SO}_{4}$. Anti-Corrosion Methods and Materials, 52, 280-285.

[36] Benali, O., Larabi, L., Mekelleche, S.M. and Harek, Y. (2006) Influence of Substitution of Phenyl Group by Naphthyl in a Diphenylthiourea Molecule on Corrosion Inhibition of Cold-Rolled Steel in $0.5 \mathrm{M} \mathrm{H}_{2} \mathrm{SO}_{4}$. Journal of Materials Science, 41, 7064-7073. https://doi.org/10.1007/s10853-006-0942-6

[37] Talati, J.D. and Gandhi, D.K. (1983) N-Heterocyclic Compounds as Corrosion Inhibitors for Aluminium-Copper Alloy in Hydrochloric Acid. Corrosion Science, 23, 1315-1332. https://doi.org/10.1016/0010-938X(83)90081-1

[38] Abood, A.A., Almubarak, A. and Abood, H.A. (2016) Experimantal and Theoretical Studies of 1-Hydroxy-2-(pyridine-3-yl)ethane-1,1diyldphosphonic Acid on Mild Steel as Anti Corrosion in Aqueous Media. International Journal of Advance Research, 4, $1-18$.

[39] Tiu, B.D.B. and Advincula, R.C. (2015) Polymeric Corrosion Inhibitors for the Oil and Gas Industry: Design Principles and Mechanism. Reactive and Functional Polymers, 95, 25-45.

[40] Bouklah, M., Benchat, N., Hammouti, B., Aouniti, A. and Kertit, S. (2006) Thermodynamic Characterisation of Steel Corrosion and Inhibitor Adsorption of Pyridazine Compounds in 0.5 $\mathrm{M} \mathrm{H}_{2} \mathrm{SO}_{4}$. Materials Letters, 60, 1901-1905.

[41] Quajai, S. and Shanks, R.A. (2005) Composition, Structure and Thermal Degradation of Hemp Cellulose after Chemical Treatments. Polymer Degradation and Stability, 89, 327-335.

[42] Groenewoud, W.M. (2005) Characterization of Polymers by Thermal Analysis. Elsever, Amsterdam. 
Submit or recommend next manuscript to SCIRP and we will provide best service for you:

Accepting pre-submission inquiries through Email, Facebook, LinkedIn, Twitter, etc. A wide selection of journals (inclusive of 9 subjects, more than 200 journals)

Providing 24-hour high-quality service

User-friendly online submission system

Fair and swift peer-review system

Efficient typesetting and proofreading procedure

Display of the result of downloads and visits, as well as the number of cited articles Maximum dissemination of your research work

Submit your manuscript at: http://papersubmission.scirp.org/

Or contact ojopm@scirp.org 